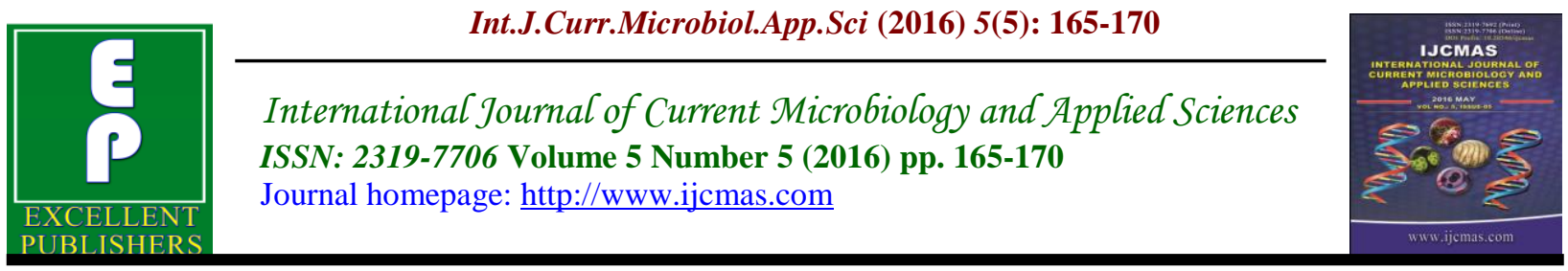

Original Research Article

http://dx.doi.org/10.20546/ijcmas.2016.505.018

\title{
Bacterial Contamination of Food Handlers at Various Restaurants in Kano State Metropolis, Kano Nigeria
}

\author{
Jibrin Yusuf Dahiru ${ }^{1 *}$, Firdausi Aliyu Abubakar ${ }^{2}$, Hamza Idris ${ }^{1}$ and \\ Saratu Abubakar Abdullahi ${ }^{1}$ \\ ${ }^{1}$ Jodhpur National University, India \\ ${ }^{2}$ Bayero University Kano, Nigeria
}

*Corresponding author

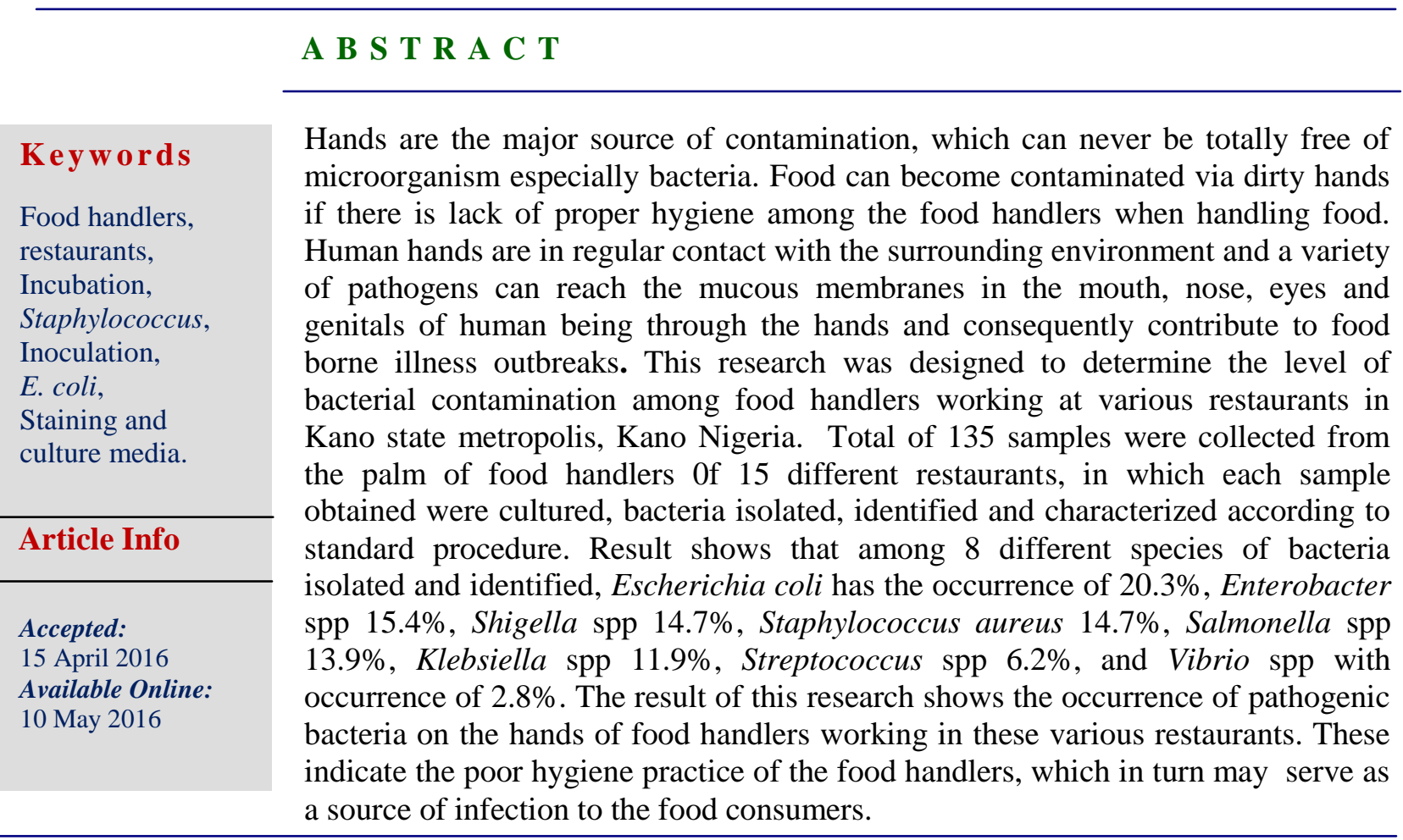

\section{Introduction}

Hands are the major source of contamination, which can never be totally free of microorganism especially bacteria. Food can become contaminated via dirty hands if there is lack of proper hygiene among the food handlers when handling food (Anuradha and Dandekar, 2014).
Although contaminated surfaces can serve as possible reservoirs for pathogenic microorganisms, studies have suggested that surfaces are not directly associated with transmission of food-borne infections to individual and the source of transmission from surfaces to patients is mainly via hand contact with the surface (Assefa et al., 
2015). Human hands are in regular contact with the surrounding environment and a variety of pathogens can reach the mucous membranes in the mouth, nose, eyes and genitals of human being through the hands and consequently contribute to foodborne illness outbreaks (Tan et al., 2013). Food handlers are the individuals playing a major role in ensuring food quality and safety throughout the sequence of producing, processing, storage, preparation and service. Consequences of food-borne outbreaks via the food handlers is a common and continual problem worldwide'. Outbreaks of food born illness have been linked to improper food handling practice at food serving establishment (Thidarat et al., 2011).

Almost $75 \%$ of food borne illness outbreaks is assumed to be related to improper food handling practices by employees in food establishments (Gizaw et al., 2013). The improper food handling practices have attributed by lack of adequate food safety knowledge. In developing countries, up to an estimated $70 \%$ of cases of diarrheal diseases are associated with the consumption of contaminated foods (Andargie et al., 2014).

Approximately 10 to $20 \%$ of food-borne disease out breaks are due to contamination by the food handle (Cheesbrough). Food handlers are those who directly engages in the handling of food, or handle the surfaces which likely to come in contact with food, for food business.

The aim and objective of this research is to access the level of bacterial contamination among food handlers working at various restaurants in Kano state metropolis, Kano Nigeria. To isolate and identify some pathogenic bacteria from the hands of food handlers.

\section{Materials and Methods}

\section{Study Area}

The study sites were various restaurants located in Kano state metropolis, Kano Nigeria.

\section{Sample Collection}

Total of 135 samples were collected from 15 different restaurants located in Kano state metropolis, Kano Nigeria. Three individuals were sampled from each restaurants and the sample collected in triplicate from each individual, collecting 9 samples from each restaurant. These samples were collected from different parts of palm of each food handlers for bacteriological analysis.

A sterile cotton swab stick was moisture in a normal saline and various parts of palm of food handler were swabbed by gentle rolling the swab stick at different part of the palm. Caution was taken not contaminate the swab, and it was place back in to its container and sealed with adhesive tape and labeled.

\section{Sterilization of Apparatus and Glassware used}

All apparatus and other glass wires used for the performance of this practical were sterilized using autoclave at $121^{\circ} \mathrm{c}$ for 15 minutes. This in order to avoid contamination during the conduct of the practical

\section{Media Preparation}

Various selective and differential media were prepared. Media prepared includeMacConkey agar, mannitol salt agar, thiosulphate citrate bile salt sucrose agar, brilliant green agar, Eosin methylene blue agar and blood agar. 


\section{Inoculation of the Culture Media}

Each sample collected was inoculated on to various selective and differential media use for the isolation of different bacterial species. This was done by tricking the surface of the agar medium using the swab stick containing the sample. And the plates were incubated at $37^{\circ} \mathrm{c}$ for about 24 hours.

\section{Plate Reading}

Various plates incubated were observed after 24 hours incubation, in which morphological characteristics, color and texture of the colonies grown on these media were observed.

\section{Identification of the Isolates}

\section{Gram Staining Technique}

Base on Gram reaction bacteria isolated were grouped in to Gram positive and Gram negative by their ability for retaining the primary stain (Gram positive) and others loses the primary stain and retained secondary stain(Gram negative).

\section{Method}

Smear of each isolate were made on a clean glass slide and fixed over Bunsen flame. A dried and fixed smear was covered with crystal violet for 1 minute It was rapidly washed with clean water. The smears were then covered with Grams iodine for 1 minute. Then the smears were decolorized using alcohol and flushed immediately with water. Smear were also covered with safranine reagent for 2 minutes, then washed with water. Then slides were dried.

\section{Microscopic Examination}

One drop of emersion oil was placed on these dried smears on the glass slide and observed under x100 objective. Gram reaction and morphological characteristics of the organism were observed and recorded.

\section{Biochemical Identification}

After identification of the Gram reaction of the isolates, the colonies were also subjected to various biochemical tests for the confirmation of the species of bacteria isolated.

Biochemical test employed are: coagulase test, oxidase test, catalase test, indol test, methyl red test, vp test, bile solubility test, citrate utilization test, motility test, and test using triple sugar ion media

\section{Results and Discussion}

In this research the overall contamination level of bacteria was high. This indicated poor personal hygiene practice of the food handlers working in this various restaurants. The high contamination level in this research was in agreement with the findings of ${ }^{[8]}$. The result shows that about $89 \%$ of the food handlers were contaminated and it was revealed out that this contamination is largely due to the poor personal hygiene practice, lack of environmental sanitation and ignorance of health promotion practice.

High occurrence of E. coli and Enterobacter spp of $20.3 \%$ and $15.4 \%$ respectively from the hands of food handlers in this research indicated contamination of hands with fecal bacteria due the inadequate hand washing practice, which was in agreement with the findings of ${ }^{[10]}$. Which reported that intestinal bacteria E. coli and Enterobacter spp have the highest contamination level reaches about $22.2 \%$ and $17.8 \%$ respectively. And they revealed out that these bacteria can be transmitted from the 
hands of these food handlers to the consumer's food, leading to food born infection. Klebsiella was also among the intestinal bacteria isolated with about $11.9 \%$ contamination level, which also indicated contamination of hands from the fecal sources.

Table.3.1 Showing the Number of Positive Sample of Bacteria Isolated among the Various Restaurants

No: of sample collected from each restaurants $=9$

\begin{tabular}{|c|l|l|c|c|c|c|c|c|}
\hline Sample Site & I & II & III & IV & V & VI & VII & VIII \\
\hline A & 3 & 2 & 3 & 1 & 2 & 1 & 0 & 0 \\
B & 3 & 1 & 1 & 2 & 0 & 2 & 0 & 1 \\
C & 3 & 2 & 3 & 1 & 2 & 1 & 2 & 0 \\
D & 2 & 1 & 1 & 2 & 2 & 1 & 0 & 0 \\
E & 2 & 1 & 1 & 2 & 1 & 2 & 1 & 0 \\
F & 1 & 1 & 1 & 2 & 1 & 2 & 1 & 1 \\
G & 3 & 2 & 2 & 2 & 2 & 1 & 0 & 0 \\
H & 1 & 1 & 1 & 1 & 1 & 1 & 0 & 0 \\
I & 1 & 2 & 2 & 2 & 2 & 1 & 0 & 0 \\
J & 2 & 2 & 1 & 1 & 1 & 0 & 1 & 0 \\
K & 2 & 2 & 2 & 0 & 1 & 1 & 1 & 1 \\
L & 1 & 0 & 0 & 0 & 0 & 2 & 1 & 0 \\
M & 1 & 2 & 1 & 2 & 1 & 0 & 1 & 0 \\
N & 1 & 1 & 0 & 1 & 2 & 1 & 0 & 0 \\
O & 3 & 2 & 2 & 2 & 2 & 1 & 1 & 0 \\
\hline
\end{tabular}

Latter A-O representing restaurants in which the samples were collected Name of bacteria isolated represented by roman number I-VIII $\mathrm{I}=$ E.coli, $\mathrm{II}=$ Enterobacter $s p p, \mathrm{III}=$ Shigella $s p p, \mathrm{IV}=$ Staphylococcus $s p p, \mathrm{~V}=$ Salmonella spp, $\mathrm{VI}=$ Klebsiella $s p$, $\mathrm{VII}=$ Streptococcus $s p$, VIII= Vibrio $s p p$.

Table.3.2 Shows the Occurrence of Bacteria Isolated from the Hands of Food Handlers. it could be Observed that E. coli has the Highest \% Occurrence (20.3\%) followed by Enterobacter spp (15.4\%), while the least \% occurrence was Vibrio spp having (2.8\%)

\begin{tabular}{|l|c|c|}
\hline \multicolumn{1}{|c|}{ Bacteria isolated } & Total positive & Contamination rate in (\%) \\
\hline E. coli & 29 & 20.3 \\
Enterobacter spp & 22 & 15.4 \\
Shigella spp & 21 & 14.7 \\
Staphylococcus aureus & 21 & 14.7 \\
Salmonella spp & 20 & 13.9 \\
Klebsiella spp & 17 & 11.9 \\
Streptococcus spp & 9 & 6.2 \\
Vibrio spp & 4 & 2.8 \\
\hline \multicolumn{1}{|c|}{ TOTAL } & 143 & 100 \\
\hline
\end{tabular}


Table.3.3 Shows the Distribution of Contamination Level of each Restaurant, in Which Restaurant $\mathrm{C}$ and $\mathrm{O}$ Have the Highest Contamination Level of (9.8\%) Each While Restaurant $\mathrm{L}$ has the Least Contamination Level of $(2.8 \%)$

\begin{tabular}{|c|c|c|}
\hline Sample Site & Total positive & Contamination level in (\%) \\
\hline A & 12 & 8.4 \\
B & 10 & 6.9 \\
C & 14 & 9.8 \\
D & 9 & 6.3 \\
E & 10 & 6.9 \\
F & 10 & 6.9 \\
G & 12 & 8.4 \\
H & 6 & 4.2 \\
I & 8 & 5.6 \\
J & 9 & 6.3 \\
K & 10 & 6.9 \\
L & 4 & 2.8 \\
M & 7 & 4.9 \\
N & 7 & 4.9 \\
O & 14 & 9.8 \\
\hline Total & 143 & 100 \\
\hline
\end{tabular}

Also this research shows that Shigella spp has about $14.7 \%$ contamination level signified poor hygiene practice of the food handlers, which when this bacteria transmitted to food may result in bacillary dysentery among the consumers. The hygienic situation of food handlers was further challenged by isolating Staphylococcus aureus with about $14.7 \%$ contamination level which may also spreads to the food and lead to staphylococcus food intoxication. Other intestinal bacteria isolated were salmonella spp with about $13.9 \%$ contamination level which also support the contamination of hands with fecal bacteria due to the inadequate hand washing practice of the food handlers, and consumption of this pathogen in the food may lead to typhoid fever infection. Streptococcus spp was also isolated in this research $6.2 \%$, this indicated possible contamination of hands with the nasal origin. And when these bacteria ingested may result in pneumonia infection. Vibrio spp were also among the bacteria isolated but the contamination level was very low $2.8 \%$ indicate contamination with the fecal matter and probably the hands contaminated by touching contaminated raw food materials like vegetables. Consuming of this pathogen in the food may leads to gastroenteritis.

Distribution of the contamination level of each restaurants shows that restaurants $\mathrm{C}$ and $\mathrm{O}$ have the highest percentage of contamination $9.8 \%$ each. This indicated that food handlers working in these lack good personal hygiene and proper environmental sanitation. It was also observed that, it may be attributed to the way managers of these restaurants use to employ small children which some were even beggars (Almajirai) assigning them in the preparation as well as the serving of food. While restaurant $\mathrm{L}$ has the lowest percentage of contamination signified good personal hygiene proper environmental 
sanitation among the food handlers working in this restaurants.

In conclusion from this research revealed that bacterial contamination among food handlers of these various restaurants was very high, because about $93 \%$ of the hands of food handlers were contaminated; E. coli has the highest percentage of $20.3 \%$ while vibrio has the lowest $2.8 \%$. Therefore an effective measure of preventing the transmission of these pathogens from the hands of food handlers to the consumer's food has to be taken care of.

\section{References}

Andargie, G., Kassu, A., Moges, F., Tirunch, M., Huruy, K. 2014. Prevalence of bacteria and intestinal parasite among food handlers in Gondar town, north west Ethiopia, J. Health Population And Nutri., 26(4): 451-455.

Anuradha, M., Dandekar, R.H. 2014. Knowledge attitude and practice among food handlers on food borne diseases. A hospital base study in tertiary care hospital. Int. J. Biomed. Adv. Res., 5(4): 2-7.

Assefa, T., Tasew, H., Wondafrash, B., Beker, J. 2015. Contamination of bacteria and associated factors among food handlers working in student cafeteria of Jimma university main campus Jimma south west Ethopia. Alternative and Integrative Med. J., 4(1): 85.

Cheesbrough, M. 2006. District laboratory practice in tropical countries part 2, second edition by tropical health tech. pp 76-90.

Costa- cruz, J.M., Cardoso, M.L., Marques, D.E. 2005. Intestinal parasite in school handlers in city of Uberlandia, Mi-nas Ggerais, brasil. Revista do instituto de mediana tropical de saopaulo., 37(5): 191-196.

Gizaw, Z., Gebrehiroot, M., Teka, Z. 2013. Food safety practice and associated factors of food handlers working in substandment in Gondar town, north west Ethiopia, Int. J. Food Sci. Nutri. Diet, 3(7): 138-146.

Syedzadi, M.M., Rafiuzzaman, S.A., Nigarin, S. 2015. Evaluation of bacterial etiology and hygiene status of food handlers in Jessore city, Bangladesh. Int. J. Biosci., 6(5): 1-7.

Sylvia, A.B., Rose, A.M., John, B.K. 2015. Hygiene practice and food contamination in managed food services facilities in Uganda, African J. Food Sci., 9(1): 31-42.

Tan, S.L., Lee, H.T., Abubakar, F., Abdulkarim, M.S., Rukayadi, Y., Mahyudin, N.A. 2013. Microbiological quality of food handlers hands at primary school in hulu Langat district Malaysia Int. Food Res. J., 20(5): 297329773.

Thidarat, C., Suwat, S., Duangjai, M. 2011. Food safety knowledge, attitude and practice of food handlers and microbiological and physical quality assessment of food for making merit for monks in Ratchathewi district, Bangkok. Asian J. Public Health, 2(1): 27-34.

\section{How to cite this article:}

Jibrin Yusuf Dahiru, Firdausi Aliyu Abubakar, Hamza Idris and Saratu Abubakar Abdullahi. 2016. Bacterial Contamination of Food Handlers at Various Restaurants in Kano State Metropolis, Kano Nigeria. Int.J.Curr.Microbiol.App.Sci. 5(5): 165-170. doi: http://dx.doi.org/10.20546/ijcmas.2016.505.018 